\title{
Correction to: A Class-Kriging Predictor for Functional Compositions with Application to Particle-Size Curves in Heterogeneous Aquifers
}

\author{
Alessandra Menafoglio ${ }^{1}$. Piercesare Secchi $^{1}$. \\ Alberto Guadagnini ${ }^{2,3}$
}

Published online: 18 January 2018

(C) International Association for Mathematical Geosciences 2018

\section{Correction to: Math Geosci (2016) 48:463-485 https://doi.org/10.1007/s11004-015-9625-7}

The original version of this article unfortunately contained a mistake.

In "Acknowledgments" the Grant Agreement No. was incorrect. The correct number is No. 636811.

The original article can be found online at https://doi.org/10.1007/s11004-015-9625-7.

Alessandra Menafoglio alessandra.menafoglio@polimi.it

1 MOX-Department of Mathematics, Politecnico di Milano, Milano, Italy

2 Dipartimento di Ingegneria Civile e Ambientale, Politecnico di Milano, Milano, Italy

3 Department of Hydrology and Water Resources, The University of Arizona, Tucson 85721, USA 